\title{
Relationship between plasma and lymphocyte linoleate in multiple sclerosis
}

\author{
W. M. TSANG, JOANNA BELIN, JEAN A. MONRO, A. D. SMITH, \\ R. H. S. THOMPSON, AND K. J. ZILKHA \\ From the Courtauld Institute of Biochemistry, The Middlesex Hospital Medical School, London, \\ and the National Hospital, Queen Square, London
}

SYNOPSIS The linoleate level in total lipids was measured in lymphocytes from control subjects and patients with multiple sclerosis. A small but significant decrease was found in cases of multiple sclerosis. The percentage composition of lymphocyte fatty acids was determined in rats fed diets with various linoleate contents. There was a correlation between lymphocyte linoleate and plasma linoleate in both humans and rats.

Previous work from this laboratory has shown that in patients with multiple sclerosis there is a lowering of the linoleate levels in platelets and erythrocytes (Gul et al., 1970) in addition to a lowering of the linoleate level in the plasma lipids (Belin et al., 1971), the latter result confirming earlier work (Baker et al., 1964; Tichy et al., 1969) and according with more recent reports (Love et al., 1974; Kalofoutis and Jullien, 1974; Crawford and Hassam, 1975; Paty et al., 1975), although some authors have failed to find lower linoleate in multiple sclerosis patients (Cumings et al., 1965; Karlsson et al., 1971; Wolfgram et al., 1975). We have now extended the studies on linoleate levels to lymphocytes and to the free (non-esterified) fatty acids of the plasma. This study is relevant to reports that free fatty acids, especially when they are polyunsaturated, can inhibit certain in vitro activities of lymphocytes (Mertin et al., 1974; Offner and Clausen, 1974) and in vivo can prolong skin graft rejection in rodents (summarised in Hughes et al., 1975). Mertin et al. (1973) suggested that in vivo these unsaturated acids may play an immunoregulatory role, which may form the basis of the beneficial effect of dietary sunflower seed oil in the treatment of multiple sclerosis (Millar et al., 1973).
Further support for the concept that a relationship may exist between fatty acid status and immunological activity arises from work with animals. It has been shown (Clausen and Møller, 1967; Selivonchick and Johnston, 1975) that animals fed a diet deficient in essential fatty acids (EFA) are more susceptible to the development of experimental allergic encephalomyelitis than those on normal diets and that the addition of linoleate to the diet exerted a pronounced protective effect.

In view of these various findings we thought that it would be valuable to examine the levels of linoleate in the lymphocytes and nonesterified fatty acids of patients with multiple sclerosis and to establish the levels of linoleate in the lymphocytes of rats fed diets in which the linoleate was varied over a wide range.

\section{METHOD}

PREPARATION OF HUMAN LYMPHOCYTES Fifty millilitre blood samples were drawn from patients with multiple sclerosis who had fasted overnight, using heparin as anticoagulant. So far as could be ascertained the patients were not supplementing their diet with polyunsaturated fatty acid. No account was taken in the study of the state of the disease. Lymphocytes were prepared by the method of Bøyum (1968). To remove platelets the lymphocytes were washed three times in $0.9 \%$ saline, being centrifuged at $100 \mathrm{~g}$ for 10 minutes between washes. 
PREPARATION OF FATTY ACID FRACTIONS Lipids were extracted from the lymphocyte pellet after the final saline wash by resuspending the pellet in $0.5 \mathrm{ml}$ saline and then using the extraction procedure of Folch et al. (1957). After taking the chloroform layer to dryness the lipid fraction was saponified and the fatty acid composition determined, as described by Belin et al. (1971). To obtain the free fatty acids 5-ml samples of plasma were extracted by the method of Hagenfeldt (1966). The methods previously described (Belin et al., 1971) were used for the methylation of the free fatty acids and also for the estimation of the total fatty acids.

EXPERIMENTS WITH RATS The animals were of the Wistar strain. The mothers were fed a fat-free diet (Nutritional Biochemicals) from the time of mating. At weaning the rats were divided into three groups and fed the fat-free diet supplemented with oil as follows: group A, $10 \%$ hydrogenated coconut oil; group $\mathrm{B}, 9 \%$ hydrogenated coconut oil plus $1 \%$ sunflower seed oil; group C, $10 \%$ sunflower seed oil. Control rats were fed the normal cubed diet ad libitum.

The animals were killed when aged 34-36 weeks. Lymphocytes were prepared from the spleen by gentle teasing with forceps in RPMI Medium 1640, then layered on to Lymphoprep (Nyegaard \& Co., Oslo), and centrifuged at $400 \mathrm{~g}$ for 10 minutes. The cells at the interface were collected and washed three times with RPMI medium 1640 (Flow Laboratories), the first centrifugation being at $180 \mathrm{~g}$ for 10 minutes and the subsequent two (to remove platelets) at $100 \mathrm{~g}$ for 10 minutes. The pellet was treated in the same way as described above for human lymphocytes.

Rat blood was drawn by heart puncture under light ether anaesthesia and treated for fatty acid determination in the same way as described for human blood.

\section{RESULTS}

OBSERVATIONS IN PATIENTS The level of total plasma linoleate when compared with 14 normal control subjects was again found to be significantly lower in this sample of 19 patients (Table 1), who were randomly selected apart from the need to take those who were not using oil supplements in the diet. A decrease in linoleate was also found in the free fatty acids. Again, a small but significant decrease was found in the lymphocyte fraction. As might be expected, a very close correlation was found

\section{TABLE 1}

MEAN ( \pm SD) PERCENTAGE OF LINOLEATE IN SERUM TOTAL LIPIDS, SERUM FREE FATTY ACIDS, AND LYMPHOCYTES IN CONTROL SUBJECTS AND PATIENTS WITH MULTIPLE SCLEROSIS

\begin{tabular}{lcrc}
\hline & Controls & $M S$ patients & $P$ \\
\hline $\begin{array}{l}\text { Total lipids } \\
\text { Non-esterified }\end{array}$ & $35.0 \pm 1.0(14)$ & $28.8 \pm 0.77(19)$ & $<0.00$ \\
$\quad$ fatty acids & $17.0 \pm 1.1(14)$ & $12.1 \pm 0.50(18)$ & $<0.00$ \\
Lymphocytes & $10.6 \pm 0.64(12)$ & $8.3 \pm 0.33(17)$ & $<0.00$ \\
\hline
\end{tabular}

between the linoleate levels in the free and total fatty acids (Fig. 1).

When a scatter diagram was prepared of the lymphocyte linoleate levels against the serum free fatty acid linoleate levels it was found that if results from the multiple sclerosis patients were plotted alone a poor correlation resultect because of the narrow range over which the values extended. The same applied if the controf 음 results were plotted alone. When control anf patient results were plotted together, however, good correlation resulted, which was furthe strengthened when results from a few patient and controls who had taken oil were addeg (Fig. 2). It thus appears that there is a correlation

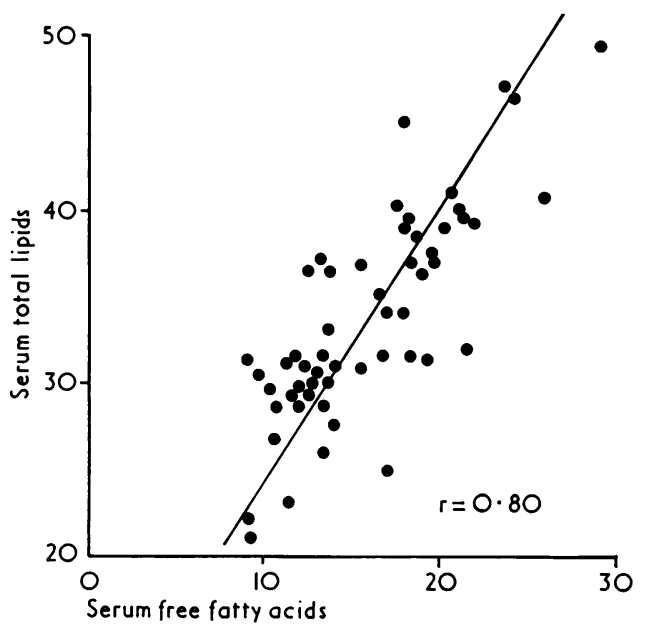

FIG. 1 Percentage linoleate in serum total lipids and in serum free fatty acids in humans. 


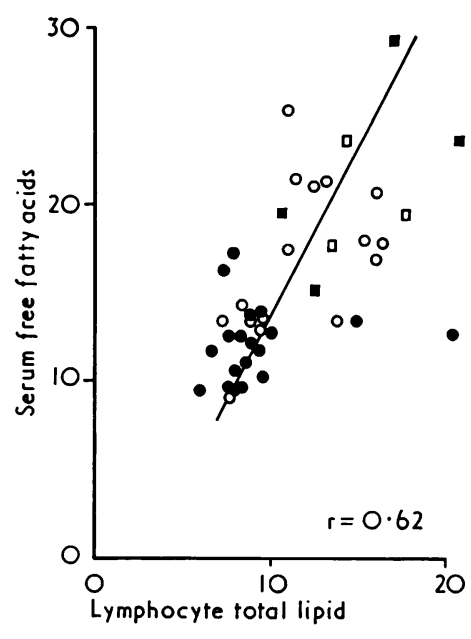

FIG. 2 Percentage linoleate in serum free fatty acids and in lymphocyte total lipids in humans. O Controls.

Controls on oil. $\bullet$ MS. $\square$ MS on oil.

$(r=0.62)$ between linoleate levels in the serum free fatty acids and in the lymphocytes which can be demonstrated provided values extend over a wide enough range. A good correlation also exists between linoleate levels in the blood total fatty acids and in the lymphocytes $(r=0.66)$.

EXPERIMENTS WITH RATS As support for the work with human lymphocytes and as the basis for a projected study of the relationship between reduced linoleate levels and sensitivity to the encephalitogenic protein, comparable studies of the lymphocyte linoleate level were made in rats on appropriate dietary regimes. The percentage compositions of the lymphocyte fatty acids as a result of the different dietary treatments (EFA deficient or supplemented with $1 \%$ or $10 \%$ sunflower seed oil) are shown in Table 2. The linoleate level can be varied from about $2-20 \%$ in animals fed the diets for many months. We are currently investigating the extent to which these changes can be brought about over shorter periods.

Over this range of values a close correlation $(r=0.93)$ is again found between linoleate levels in lymphocytes and blood (Fig. 3). It is perhaps not surprising that if the animal is severely deprived of linoleate the acid will be lacking in both lymphocytes and blood. However, even using the results from animals fed sufficient linoleate in the diet-that is, omitting the results from those animals on the EFA deficient diet-a highly significant correlation is found $(r=0.75)$.

\section{DISCUSSION}

These and previous results show that lowered linoleate levels are found in the plasma fatty acids, both esterified and free, and in three of the major blood cell types in patients with multiple sclerosis.

The finding, reported for the first time, of a decrease of the linoleate level in the free fatty acids may well be of importance because these are the more likely to influence the level of linoleate in the membrane, since it seems from work with cells in culture that they derive their membrane fatty acids primarily from free fatty acids, although other types of lipids make a

TABLE 2

MEAN ( \pm SD) WEIGHT PERCENTAGE COMPOSITION OF LYMPHOCYTE FATTY ACIDS IN RATS ON DIFFERENT DIETS

\begin{tabular}{|c|c|c|c|c|c|c|c|c|}
\hline \multirow[b]{2}{*}{ Diet } & \multirow[b]{2}{*}{ No. of rats } & \multicolumn{7}{|c|}{ Fatty acid } \\
\hline & & Palmitic & Palmitoleic & Stearic & Oleic & Eicosatrienoic & Linoleic & Arachidonic \\
\hline Normal & 5 & $\begin{array}{c}30.5 \\
\pm 0.31\end{array}$ & $\begin{array}{c}3.9 \\
\pm 0.24\end{array}$ & $\begin{array}{c}17.6 \\
\pm 0.36\end{array}$ & $\begin{array}{c}18.2 \\
\pm 0.67\end{array}$ & - & $\begin{array}{c}12.3 \\
\pm 0.44\end{array}$ & $\begin{array}{c}17.5 \\
\pm 0.67\end{array}$ \\
\hline Diet A (deficient) & 3 & $\begin{array}{c}27.3 \\
\pm 0.71\end{array}$ & $\begin{array}{r}6.8 \\
\pm 0.24\end{array}$ & $\begin{array}{r}16.2 \\
\pm 1.23\end{array}$ & $\begin{array}{c}28.4 \\
\pm 0.72\end{array}$ & $\begin{array}{c}13.0 \\
\pm 0.11\end{array}$ & $\begin{array}{r}2.2 \\
+0.4\end{array}$ & $\begin{array}{r}6.01 \\
+0.69\end{array}$ \\
\hline Diet B ( $1 \%$ sunflower seed oil) & 5 & $\begin{array}{c}28.0 \\
\pm 0.51\end{array}$ & $\begin{array}{r}5.0 \\
\pm 0.32\end{array}$ & $\begin{array}{r}18.2 \\
\pm 0.62\end{array}$ & $\begin{array}{c}17.3 \\
\pm 0.89\end{array}$ & - & $\begin{array}{c}13.3 \\
\pm 0.43\end{array}$ & $\begin{array}{c}18.2 \\
+1.75\end{array}$ \\
\hline Diet C ( $10 \%$ sunflower seed oil) & 5 & $\begin{array}{c}27.2 \\
\pm 0.70\end{array}$ & $\begin{array}{c}3.3 \\
\pm 0.38\end{array}$ & $\begin{array}{c}16.9 \\
\pm 0.90\end{array}$ & $\begin{array}{c}14.9 \\
\pm 0.62\end{array}$ & - & $\begin{array}{r}18.2 \\
\pm 1.0\end{array}$ & $\begin{array}{l}19.5 \\
\pm 0.74\end{array}$ \\
\hline
\end{tabular}




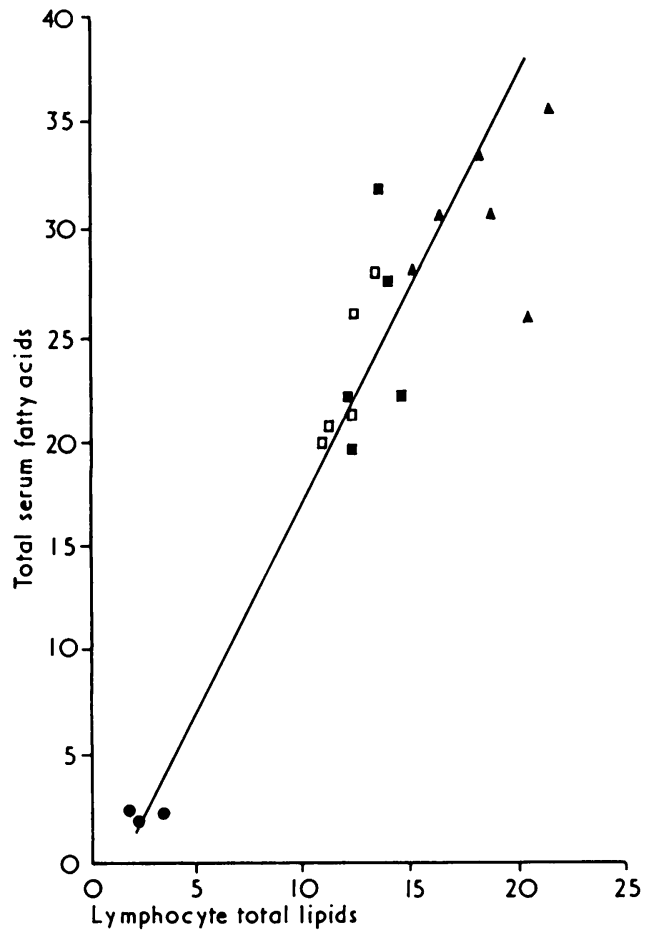

FIG. 3 Percentage linoleate in serum free fatty acids and lymphocyte total lipids in rats on diets of varying linoleate content. $\square$ Normal diet. - Deficient diet.

Deficient diet supplemented with $1 \%$ sunflower seed oil. $\Delta$ Deficient diet supplemented with $10 \%$ sunflower seed oil.

small contribution (Bailey et al., 1973). Furthermore, the observed changes in linoleate in the free fatty acids are more relevant to the in vitro conditions used by Mertin et al. (1974) in their study of the effect of polyunsaturated fatty acids on lymphocyte function.

The question remains to be resolved whether the low levels in the cells arise because of the low plasma levels, since, as we have shown here and previously (Gul et al., 1970), there is a correlation between levels in plasma and each of these cell types, or whether there is some other cause of the low linoleate levels in cells.

The results further show that lymphocyte linoleate levels are susceptible to change by alteration in diet, and in particular that the feeding of sunflower seed oil to patients will increase the level of linoleate in their lymphocytes. To what extent this is the basis of the beneficial effects reported for the oil is another question to be resolved in the future. It will also be of interest to investigate the effect of these changes on a number of lymphocyte function tests with a view to assessing the extent to which it may be possible to modify by dietary supplementation with linoleate lymphocyte reactivity in patients with multiple sclerosis.

We thank the Multiple Sclerosis Society for financial support, and Miss Sheila Morgan for her excellent technical assistance.

\section{REFERENCES}

Bailey, J. M., Howard, B. V., and Tillman, S. F. (1973). Lipid metabolism in cultured cells. 11. Utilization of serum triglycerides. Journal of Biological Chemistry, 248, 1240-1247.

Baker, R. W. R., Thompson, R. H. S., and Zilkha, K. J. (1964). Serum fatty acids in multiple sclerosis. Journal of Neurology, Neurosurgery, and Psychiatry, 27, 408-414.

Belin, J., Pettet, N., Smith, A. D., Thompson, R. H. S., and Zilkha, K. J. (1971). Linoleate metabolism in multiple sclerosis. Journal of Neurology, Neuro surgery, and Psychiatry, 34, 25-29.

Bøyum, A. (1968). Isolation of leucocytes from human. blood. Scandinavian Journal of Clinical Laboratory Investigation, 97, suppl. 31-50.

Clausen, J., and Møller, J. (1967). Allergic encephalomyelitis induced by brain antigen after deficiency in polyunsaturated fatty acids during myelination. Acta Neurologica Scandinavica, 43, 375-388.

Crawford, M. A., and Hassam, A. G. (1975). Diagnostic test for multiple sclerosis. British Medical Journal, 1, 150-151.

Cumings, J. N., Shortman, R. C., and Skrbic, T. (1965). Lipid studies in the blood and brain in multiple sclerosis and motor neurone disease. Journal of Clinical Pathology, 18, 641-644.

Folch, J., Lees, M., and Sloane Stanley, G. H. (1957). A simple method for the isolation and purification of total lipids from animal tissues. Journal of Biological Chemistry, 226, 497-509.

Gul, S., Smith, A. D., Thompson, R. H. S., Payling Wright, H. and Zilkha, K. J. (1970). Fatty acid composition of phospholipids from platelets and erythrocytes in multiple sclerosis. Journal of Neurology, Neurosurgery, and Psychiatry, 33, 506-510.

Hagenfeldt, L. (1966). A gas chromatographic method for the determination of individual free fatty acids in plasma. Clinica Chimica Acta, 13, 266-268. 
Hughes, D., Caspary, E. A., and Wisniewski, H. M. (1975). Immunosuppression by linoleic acid. Lancet, 2, 501-502.

Kalofoutis, A., and Jullien, G. (1974). A study of serum fatty acids in neurological diseases. Biochimie, 56, 623-624.

Karlsson, I., Alling, C., and Svennerholm, L. (1971). Major plasma lipids and their fatty acid composition in multiple sclerosis and other neurological diseases. Acta Neurologica Scandinavica, 47, 403-412.

Love, W. C., Cashel, A., Reynolds, M., and Callaghan, N. (1974). Linoleate and fatty-acid patterns of serum lipids in multiple sclerosis and other diseases. British Medical Journal, 3, 18-21.

Millar, J. H. D., Zilkha, K. J., Langman, M. J. S., Payling Wright, H., Smith, A. D., Belin, J., and Thompson, R. H. S. (1973). Double-blind trial of linoleate supplementation of the diet in multiple sclerosis. British Medical Journal, 1, 765-768.

Mertin, J., Hughes, D., and Stewart-Wynne, E. (1974). P.H.A. transformation in M.S.: inhibition by linoleic acid. Lancet, 1, 1005-1005.
Mertin, J., Shenton, B. K., and Field, E. J. (1973). Unsaturated fatty acids in multiple sclerosis. British Medical Journal, 2, 777-778.

Offner, H., and Clausen, J. (1974). Inhibition of lymphocyte response to stimulants induced by unsaturated fatty acids and prostaglandins. Lancet, 2, 400-401.

Paty, D. W., Cousin, H. K., and McDonald, L. E. (1975). Linoleic acid in multiple sclerosis. Lancet, 1, 11971198.

Selivonchick, D. P., and Johnston, P. V. (1975). Fat deficiency in rats during development of central nervous system and susceptibility to experimental allergic encephalomyelitis. Journal of Nutrition, 105, 288-300.

Tichy, J., Vymazal, J., and Michalec, C. (1969). Serum lipoproteins, cholesterol esters, and phospholipids in multiple sclerosis. Acta Neurologica Scandinavica, 45, 32-40.

Wolfgram, F., Myers, L., Ellison, G., and Knipprath, W. (1975). Serum linoleic acid in multiple sclerosis. Neurology (Minneap.), 25, 786-788. 